\title{
Impact of non-insulin dependent diabetes mellitus on bone structure biomarkers in postmenopausal obese women
}

\begin{abstract}
Background: At menopause, there is reduction in both cortical and trabecular bone associated with low estrogen hormone secretion. In addition, non-insulin dependent diabetes mellitus (NIDDM) characterized with poor quality and microarchitecture of bone that increase the risk of fracture.

Objective: As the influence of NIDDM on markers of bone turnover and density of bone after menopause is a matter of debate and inconclusive, so the aim of this study was to measure the impact of NIDDM on bone mineral status among obese postmenopausal women.

Material and Methods: One hundred thirty eight obese postmenopausal Saudi women with body mass index (BMI) ranged from 31 to $36 \mathrm{Kg} / \mathrm{m} 2$, were selected from the out-patient clinic of Gynecology and Obstetrics Department at the King Abdalziz University Hospital in Jeddah area. Initially, a physician at King Abdulaziz University Hospital examined all participants; their medical history was taken to collect information about general condition, physical activity and current medications. Participants were allocated into two study groups; group (A) 77 diabetic postmenopausal women with fasting blood sugar $\geq 7.0 \mathrm{mmol} / 1$ or post-prandial blood sugar $\geq 11.1 \mathrm{mmol} / 1$ and glycosylated hemoglobin (HbAlc\%) $>6.5 \%$, and group (B) 43 non-diabetic postmenopausal women.
\end{abstract}

Results: The mean values of the Osteocalcin and P1NP as bone turn over markers for bone formation were significantly lower in diabetic patients than non-diabetic patients, while both CTX and NTX as bone turn over markers for bone resorption were non-significantly lower in diabetic patients than non-diabetic patients. In the other hand, the mean values of BMD of the lumbar spine L2-L4 total, the femoral neck and radius were significantly greater in diabetic patients than non-diabetic patients.

Conclusion: Non-insulin dependent diabetes mellitus remarkably reduce bone turnover biomarkers in obese postmenopausal women.

Keywords: bone mineral density, bone turnover markers, menopause, non-insulin dependent diabetes mellitus
Volume 7 Issue I - 2017

\author{
Essam H Jiffri, Mohammed H Saiem Al Dahr \\ Department of Medical Laboratory Technology, King Abdulaziz \\ University, Saudi Arabia
}

\begin{abstract}
Correspondence: Essam H Jiffri, Department of Medical Laboratory Technology, Faculty of Applied Medical Sciences, King Abdulaziz University, P.O. Box 80324, Jeddah, 21 589, Saudi Arabia, Email ejiff@hotmail.com
\end{abstract}

Received: May 09, 2017 | Published: July 06, 2017
Abbreviations: BMI, body mass index; SBP, systolic blood pressure; DBP, diastolic blood pressure; $\mathrm{PTH}$, parathyroid hormone

\section{Introduction}

Non-insulin dependent diabetes mellitus (NIDDM) is most commonly current metabolic disorder as it affects more than 385 million and it is expected to reach about 590million by 2035 worldwide, ${ }^{1}$ so that NIDDM has huge economic burden and adverse medical effects as there is a risk of fracture due to bone fragility in spite many researches confirm normal or even higher bone mineral density (BMD) that controls especially with long history of diabetes and poor glycemic control. ${ }^{2-4}$

The risk of bone fracture is higher among patients with NIDDM, for example, the relative risk ratio of hip fracture is 1.7 among NIDDM compared to non-diabetics. ${ }^{5}$ Similarly, Yamaguchi \& Sugimoto ${ }^{6}$ in their meta-analyses of several researches concluded that the risk of hip fracture is $1.4-1.7$ folds greater in NIDDM and the risk of vertebral fracture also higher among NIDDM than non-diabetics, ${ }^{6}$ although the BMD did not diminished which indicate the fragility of bone in NIDDM was due to deterioration in bone quality rather than reduced bone mass. ${ }^{7-9}$

Osteoporosis is one of the most common bone metabolic diseases, more frequently reported in postmenopausal women. ${ }^{10}$ It is reported to be the cause of fracture in $30 \%$ of this population. Apart from aging and hormonal changes, which are directly linked with osteoporosis, many studies have pointed out certain underlying diseases and the consumption of specific medications as the culprit. ${ }^{11}$ Diabetes is reported to be one of these conditions as its sufferers are reported to be up to 12 times more likely to experience an osteoporotic fracture in their life. ${ }^{12,13}$

Postmenopausal women are shown to be more prone to developing diabetes because of various reasons. Aging negatively affects carbohydrate metabolism in the body, increasing the risk of developing insulin resistance and thus NIDDM. ${ }^{14}$ The higher rate of obesity and lower levels of physical activity noticed in this group also aggravate the condition. ${ }^{15}$ According to existing reports, this group is also more 
susceptible to osteoporosis mainly because of the hormonal changes that occur during aging. Many researchers, therefore, are looking for associations between osteoporosis and diabetes; there is, however, no consensus in this regard. ${ }^{16,17}$ As the influence of NIDDM on markers of bone turnover and density of bone after menopause is a matter of debate and inconclusive, so the aim of this study was to measure the impact of NIDDM on bone turnover markers and bone mineral status among obese postmenopausal women.

\section{Materials and methods}

\section{Subjects}

One hundred twenty obese postmenopausal Saudi women with body mass index (BMI) ranged from 31 to $36 \mathrm{Kg} / \mathrm{m}^{2}$, were selected from the out-patient clinic of Gynecology and Obstetrics Department at the King Abdalziz University Hospital in Jeddah area. Initially, a physician at King Abdulaziz University Hospital examined all participants; their medical history was taken to collect information about general condition, physical activity and current medications. Inclusion criteria of this study were postmenopausal women aged 47-59years and taking no medication affecting bone metabolism and hormone-replacement therapy. However, exclusion criteria included smokers and patients suffering from congestive heart failure; uncontrollable cardiac arrhythmias, hypertension, chronic liver disease, renal failure, previous pathological fractures, thyroid or parathyroid disorders, hematologic diseases, cancer and pregnancy. Participants were allocated according to their diabetic status into two groups; group (A) 77 diabetic postmenopausal women with fasting blood sugar $\geq 7.0 \mathrm{mmol} / 1$ or post-prandial blood sugar $\geq 11.1 \mathrm{mmol} / 1$ and glycosylated hemoglobin $(\mathrm{HbA} 1 \mathrm{c} \%)>6.5 \%,{ }^{18}$ and $\operatorname{group}(\mathrm{B}) 43$ non-diabetic postmenopausal women. The Ethical Committee of the Faculty of Applied Medical Sciences, King Abdulaziz University, approved this study. All participants signed a written informed consent.

\section{Measurements}

a. Body mass index: Body mass index (BMI) was calculated on the basis of weight (kilograms) and height (meters), and subjects were classified as normal weight (BMI $18.5-24.9 \mathrm{Kg}$ / $\left.\mathrm{m}^{2}\right)$, overweight $\left(\right.$ BMI $\left.25-29.9 \mathrm{Kg} / \mathrm{m}^{2}\right)$, and obese $(\mathrm{BMI} \geq 30 \mathrm{Kg} /$ $\left.\mathrm{m}^{2}\right)$.

b. Bone turnover biochemical markers measurement: An overnight fasting venous blood samples were withdraw between 7:30 A.M. and 9:00 A.M., centrifuged and stored

Table I Baseline and demographic characteristics of all study participants at $-70^{\circ} \mathrm{C}$ until assayed. Bone formation biomarkers were measured by ELISA N-mid Osteocalcin was used to measure osteocalcin (IDS Ltd., Scottsdale, AZ, USA) and RIA (IDS Ltd., Fountain Hills, AZ, USA) was used measure Procollagen Type 1 N-Terminal Propeptide (P1NP). ${ }^{19}$ However, bone resorption biomarkers were measured by ELISA (IDS Ltd.) which was used to measure serum C-terminal telopeptides of Type I collagen (CTX) and ELISA (Inverness Medical, Princeton, NJ, USA) was used to measure serum N-telopeptide (NTX). ${ }^{20}$ All biomarkers were measured in the same session and day to avoid inter-day variability.

c. Bone mineral density measurement: Lumbar vertebrae (L2-L4), neck of the femur and radius bone mineral density were measured with Dual Energy X-Ray Absorptiometry ((DXA) GE Lunar Prodigy enCORE software version 8.80, GE Medical Systems, Madison WI) where the measured values were recorded as $\mathrm{g} / \mathrm{cm}^{2}$.

\section{Statistical analysis}

Independent t-test was used to compare differences between both groups. Statistical analysis of data was performed using SPSS (Chicago, IL, USA) version 17. All data were presented as mean \pm SD $(\mathrm{P}<0.05)$

\section{Results}

One hundred thirty eight obese postmenopausal Saudi women, their menopause duration ranged from 3-7years and their BMI ranged from 31 to $36 \mathrm{Kg} / \mathrm{m}^{2}$. Participants were allocated into 2 groups; group (A) 77 diabetic postmenopausal women and group (B) 43 healthy postmenopausal women. The diabetic study and non-diabetic group mean of age was $54.37 \pm 5.16$ and $55.82 \pm 4.91$ years respectively, where the menopause duration mean was $4.26 \pm 1.22$ and $5.71 \pm 1.13$ years, respectively. The comparison between the groups regarding the baseline characteristics reveal no significant differences except in fasting blood glucose and glycosylated hemoglobin which were significantly greater in diabetic than non-diabetic patients.

The mean values of the Osteocalcin and P1NP as bone turn over markers for bone formation were significantly lower in diabetic patients than non-diabetic patients, while both CTX and NTX as bone turn over markers for bone resorption were non-significantly lower in diabetic patients than non-diabetic patients. In the other hand, the mean values of BMD of the lumbar spine L2-L4 total, the femoral neck and radius were significantly greater in diabetic patients than non-diabetic patients (Tables $1 \& 2$ ).

\begin{tabular}{llll}
\hline Characteristic & Diabetic & Non-Diabetic & Significance \\
\hline Age (years) & $54.37 \pm 5.16$ & $55.82 \pm 4.91$ & $\mathrm{P}>0.05$ \\
BMI $\left(\mathrm{kg} / \mathrm{m}^{2}\right)$ & $32.52 \pm 3.48$ & $33.67 \pm 3.85$ & $\mathrm{P}>0.05$ \\
Menopause duration (year) & $4.26 \pm 1.22$ & $5.7 \mathrm{I} \pm 1.13$ & $\mathrm{P}>0.05$ \\
SBP $(\mathrm{mm} \mathrm{Hg})$ & $132.64 \pm 9.8 \mathrm{I}$ & $120.52 \pm 6.93$ & $\mathrm{P}>0.05$ \\
DBP $(\mathrm{mm} \mathrm{Hg})$ & $80.26 \pm 5.37$ & $77.32 \pm 4.18$ & $\mathrm{P}>0.05$ \\
Calcium $(\mathrm{mg} / \mathrm{dl})$ & $8.74 \pm 0.81$ & $8.96 \pm 0.75$ & $\mathrm{P}>0.05$ \\
PTH $(\mathrm{pmol} / \mathrm{L})$ & $2.61 \pm 1.39$ & $2.45 \pm 1.12$ & $\mathrm{P}>0.05$ \\
Albumin $(\mathrm{mg} / \mathrm{dL})$ & $4.53 \pm 0.62$ & $4.76 \pm 0.73$ & $\mathrm{P}>0.05$ \\
\hline
\end{tabular}


Table Continued...

\begin{tabular}{llll}
\hline Characteristic & Diabetic & Non-Diabetic & Significance \\
\hline Urea $(\mathrm{mg} / \mathrm{dL})$ & $32.42 \pm 4.25$ & $31.15 \pm 5.14$ & $\mathrm{P}>0.05$ \\
FBS $(\mathrm{mg} / \mathrm{dL})$ & $175.67 \pm 11.24^{*}$ & $93.43 \pm 7.32$ & $\mathrm{P}<0.05$ \\
HbAlc $(\%)$ & $7.58 \pm 1.62^{*}$ & $5.11 \pm 0.83$ & $\mathrm{P}<0.05$
\end{tabular}

BMI, body mass index; SBP, systolic blood pressure; DBP, diastolic blood pressure; PTH, parathyroid hormone; FPG, fasting blood glucose; HBA Ic, glycosylated hemoglobin

*indicates a significant difference between the two groups, $\mathrm{P}<0.05$.

Table 2 The mean value and the significance values of different parameters in both groups

\begin{tabular}{|c|c|c|c|}
\hline & \multicolumn{2}{|l|}{ Mean士SD } & \multirow{2}{*}{ Significance } \\
\hline & Diabetic & Non-diabetic & \\
\hline PINP (ng/ml) & $32.73 \pm 6.48$ & $55.25 \pm 7.91$ & $P<0.05$ \\
\hline Osteocalcin (nmol/L) & $4.12 \pm 1.46$ & $6.57 \pm 2.38$ & $P<0.05$ \\
\hline CTX (ng/ml) & $0.35 \pm 0.17$ & $0.58 \pm 0.19$ & $P<0.05$ \\
\hline NTX (nmol/BCE/L) & $12.85 \pm 3.14$ & $|8.73 \pm 4.2|$ & $P<0.05$ \\
\hline BMD of lumbar spine L2-L4 total $\left(\mathrm{g} / \mathrm{cm}^{2}\right)$ & $0.93 \pm 0.15$ & $0.8 I \pm 0.1 I$ & $P<0.05$ \\
\hline Femoral neck $\left(\mathrm{g} / \mathrm{cm}^{2}\right)$ & $0.88 \pm 0.16$ & $0.75 \pm 0.13$ & $P<0.05$ \\
\hline BMD of radius $\left(\mathrm{g} / \mathrm{cm}^{2}\right)$ & $0.64 \pm 0.12$ & $0.53 \pm 0.09$ & $P<0.05$ \\
\hline
\end{tabular}

PINP, procollagen type I n-terminal propeptide; CTX, c-terminal telopeptide; NTX, n-terminal telopeptide; BMD, bone marrow density

*indicates a significant difference, $\mathrm{P}<0.05$.

\section{Discussion}

Osteoporosis is a major medical problem, especially in Asia, as about $50 \%$ of all hip fracture all over the world will affect Asian populations. ${ }^{21}$ Age-related bone mass loss that starts with the $4^{\text {th }}$ decade of life induces fragility fracture in postmenopausal women. ${ }^{22-24}$ In the other hand, the incidence of osteoporosis among patients with NIDDM is progressively increases that increase the risk of vertebral and hip fractures. ${ }^{25,26}$ As the influence of NIDDM on markers of bone turnover and density of bone after menopause is a matter of debate and inconclusive, so that this study was designed to measure the impact of NIDDM on bone mineral status among obese postmenopausal women.

Concerning bone mineral density, results of our study proved that that BMD values in diabetic patients for lumbar L2-L4 total $\mathrm{BMD}$, femoral neck BMD and radius were higher than non-diabetic postmenopausal patients, these results are consistent with many previous researches, ${ }^{27-30}$ which proved that values of BMD values were better in NIDDM patients than the non-diabetics. Although there is remarkable increase bone destruction is in the postmenopausal period as reduction in estrogen induce osteoclasts released from the bone marrow ${ }^{31-33}$ delayed bone loss in postmenopausal women with NIDDM. ${ }^{29,30}$ Similarly, Van Daele et al.. ${ }^{34}$ \& Isaia et al. ${ }^{35}$ confirmed that values of BMD were higher in postmenopausal patients with NIDDM relative to postmenopausal control women associated with a lower rate of non-vertebral fractures. The possible cause of greater value of BMD may due to the extra mechanical loading on bone induced by obesity associated with NIDDM in addition to relative increased levels of some circulating hormonal as parathormone, leptin, insulin, adiponectin and estrogen which stimulate bone deposition in patients with NIDDM. ${ }^{36,37}$
Regarding the values of bone turnover markers, the results of our study revealed that osteocalcin and P1NP levels as bone turn over markers for bone formation were significantly lower in diabetic patients than non-diabetic postmenopausal women. These results are consistent with several previous studies that reported low osteocalcin $^{38-44}$ and $\mathrm{P} 1 \mathrm{NP}^{45,46}$ among patients with NIDDM. Our finding that supports the concept of lower bone formation biomarkers in NIDDM than non-diabetics was due to impaired osteoblast function associated with high glucose levels among diabetics. ${ }^{47-49}$ Moreover, we found that CTX and NTX as bone turn over markers for bone resorption were significantly lower in diabetic patients than non-diabetic patients, so that these results indicate delayed bone destruction in patients with NIDDM. Our resulted agreed with Akin et al., ${ }^{50}$ found that BMD values of lumbar spine in diabetic patients were higher than healthy postmenopausal patients as osteocalcin and $\mathrm{N}$-telopeptide/creatinine $(\mathrm{NTx} / \mathrm{Cr})$ values were significantly lower in diabetic patients than healthy postmenopausal patients..$^{50}$

In contrary, Razi \& Esmaili $\mathrm{M}^{51}$ measured bone mineral density and 110 Iranian postmenopausal women and divided them into diabetic group and non-diabetic group; they proved no significant differences in BMD or bone turnover markers between both groups. ${ }^{51}$ These results contradicted with our results due to participants baseline criteria as authors selected patients with relatively longer menopause duration and the age of the selected sample were greater than our study In addition, Saeed et al. ${ }^{52} \&$ Shu et al., ${ }^{53}$ conducted cross sectional studies among postmenopausal obese women with NIDDM and age matched non-diabetic postmenopausal women and they found postmenopausal women with NIDDM have lower bone turnover markers than nondiabetic control subjects in addition to no significant differences in BMD between both groups, again these results contradicted with our results due to participants baseline criteria as authors selected patients 
with relatively longer menopause duration and the age of the selected sample were greater than our study in addition to selected over-weight non-diabetic postmenopausal women as control subjects.

The possible mechanism for altered bone turnover markers in patients with NIDDM may be due to hyperglycemia that induce generation of advanced glycation products (AGEs) which interact with AGE receptors (R-AGEs) that adversely affect bone turnover, ${ }^{54}$ reduce activity of osteoblast cell $\mathrm{s}^{55}$ and increase activity of osteoclast cells. ${ }^{56}$ Moreover, AGEs induce brittle scaffolding bone structural arrangement as they adversely affect the structural cross-linking of collagen in bone which resulted in poorer structural integrity of bone. ${ }^{57-59}$ However, chronic hyperglycemia is associated glycosuria that leads to hypercalciuria that increase calcium washout of bone which adversely affect bone quality. ${ }^{54}$ Finally, increased level of oxidative stress induced increases in AGEs, and poor insulin sensitivity may be additional potential cause of reduced bone turnover and further risk of fragility fracture in

\section{Conclusion}

Non-insulin dependent diabetes mellitus remarkably reduce bone turnover biomarkers in obese postmenopausal women.

\section{Acknowledgements}

None.

\section{Conflict of interest}

The author declares no conflict of interest.

\section{References}

1. IDF Diabetes Atlas 2014.

2. Dede AD, Tournis S, Dontas I, et al. Type 2 diabetes mellitus and fracture risk. Metabolism. 2014;63(12):1480-490

3. Forst T, Pfützner A, Kann P, et al. Peripheral osteopenia in adult patients with insulin-dependent diabetes mellitus. Diabet Med. 1995;12(10):874849 .

4. Roy B. Biomolecular basis of the role of diabetes mellitus in osteoporosis and bone fractures. World J Diabetes. 2013;4(4):101-113.

5. Hanley DA, Brown JP, Tenenhouse A, et al. Associations among disease conditions, bone mineral density, and prevalent vertebral deformities in men and women 50 years of age and older: cross-sectional results from the Canadian Multicentre Osteoporosis Study. J Bone Miner Res. 2003;18(4):784-790.

6. Yamaguchi T, Sugimoto T. Bone metabolism and fracture risk in type 2 diabetes mellitus [Review]. Endocr J. 2011;58(8):613-624.

7. Abdulameer SA, Sulaiman SA, Hassali MA, et al. Osteoporosis and type 2 diabetes mellitus: what do we know, and what we can do? Patient Prefer Adherence. 2012;6:435-448.

8. Leslie WD, Rubin MR, Schwartz AV, et al. Type 2 diabetes and bone. $J$ Bone Miner Res. 2012;27(11):2231- 2237.

9. Vestergaard P. Discrepancies in bone mineral density and fracture risk in patients with type 1 and type 2 diabetes-a meta-analysis. Osteoporos Int. 2007;18(4):427-444.

10. Wade SW, Strader C, Fitzpatrick LA, et al. Estimating prevalence of osteoporosis: examples from industrialized countries. Arch Osteoporos. 2014;9:1-182.

11. Scheen AJ. Diabetes mellitus in the elderly: insulin resistance and/or impaired insulin secretion? Diabetes Metab. 2005;31(2):5S27-5S34.
12. Nicodemus KK, Folsom AR Iowa Women's Health Study. Type 1 and type 2 diabetes mellitus and incident hip fractures in postmenopausal women. Diabetes Care. 2001;24(7):1192-1197.

13. Leidig-Bruckner G, Ziegler R. Diabetes mellitus a risk factor for osteoporosis? Exp Clin Endocrinal Diabetes. 2001;109(Supp 2):S493S514.

14. Ziegler K. Diabetes mellitus and bone metabolism. Horm Metab Res Suppl. 1992;26(1):90-94.

15. Lambers S, Van Laethem C, Van Acker K, et al. Influence of combined exercise training on indices of obesity, diabetes and cardiovascular risk in type 2 diabetes patients. Clin Rehabil. 2008;22(6):483-492.

16. Leidig-Bruckner G, Grobholz S, Bruckner T, et al. Prevalence and determinants of osteoporosis in patients with type 1 and type 2 diabetes mellitus. BMC Endocr Disord. 2014;14:1-33.

17. Kurra S, Fink DA, Siris ES. Osteoporosis-associated fracture and diabetes. Endocrinol Metab Clin North Am. 2014;43(1):233-243.

18. American Diabetes Association. Diagnosis and classification of diabetes mellitus. Diabetes Care. 2010;33(Suppl 1):62S-69S.

19. Rosenquist C, Qvist P, Bjarnason N, et al. Measurement of a more stable region of osteocalcin in serum by ELISA with two monoclonal antibodies. Clin Chem. 1995;41(10):1439-1445.

20. Shu A, Yin MT, Stein E, et al. Bone structure and turnover in type 2 diabetes mellitus. Osteoporos Int. 2012;23(2):635-641.

21. Lau EM, Leung PC, Kwok T, et al. The determinants of bone mineral density in Chinese men-results from Mr. Os (Hong Kong), the first cohort study on osteoporosis in Asian men. Osteoporos Int. 2006;17(2):297303.

22. Vasikaran S, Cooper C, Eastell R, et al. International Osteoporosis Foundation and International Federation of Clinical Chemistry and Laboratory Medicine position on bone marker standards in osteoporosis. Clin Chem Lab Med. 2011;49(8):1271-1274.

23. Szulc P, Delmas PD. Biochemical markers of bone turnover: potential use in the investigation and management of postmenopausal osteoporosis. Osteoporos Int. 2008;19:1683-1704.

24. Beitz R, Dören M. Physical activity and postmenopausal health. $J B r$ Menopause Soc. 2004;10(2):70-74.

25. Rasul S, Ilhan A, Wagner L, et al. Diabetic Polyneuropathy Relates to Bone Metabolism and Markers of Bone Turnover in Elderly Patients With Type 2 Diabetes: Greater Effects in Male Patients. Gender Medicine. 2012;9(3):187-196.

26. Vestergaard P. Discrepancies in bone mineral density and fracture risk in patients with type 1 and type 2 diabetes a meta-analysis. Osteoporos Int. 2007;18(4):427-444

27. Wakasugi $M$, Wakao $R$, Tawata $M$, et al. Bone mineral density measured by dual energy X-ray absorptiometry in patients with noninsulindependent diabetes mellitus. Bone. 1993;14(1):29-33.

28. Stolk RP, Van Daele PL, Pols HA, et al. Hyperinsulinemia and bone mineral density in an elderly population: The Rotterdam study. Bone. 1996;18(6):545-549.

29. Piepkorn B, Kann P, Forst T, et al. Bone mineral density and bone metabolism in diabetes mellitus. Horm Metab Res. 1997;29(11):584591.

30. Krakauer JC, McKenna MJ, Buderer NF, et al. Bone loss and turnover in diabetes. Diabetes. 1995;44(7):775-782.

31. Yilmaz N, Bayram M, Erbagci AB, et al. Diagnostic value of biochemical markers of bone turnover and postmenopausal osteoporosis. Clin Chem Lab Med. 1999;37(2):137-143. 
32. TakahashiM, Kushida K, HoshinoH, et al. Evaluation of bone turnover in postmenopause, vertebral fracture, and hip fracture using biochemical markers for bone formation and resorption. $J$ Endocrinol Invest. 1997;20(3):112-117

33. Eastell R, Blumsohn A. The value of biochemical markers of bone turnover in osteoporosis. $J$ Rheumatol. 1997;24(6):1215-1217.

34. Isaia GC, Ardissone P, Di Stefano M, et al. Bone metabolism in Type 2 diabetes mellitus. Acta Diabetol. 1999;36(1-2):35-38.

35. Van Daele PL, Stolk RP, Burger H, et al. Bone density in noninsulin dependent diabetes mellitus. The Rotterdam Study. Ann Intern Med. 1995;122(6):409-414.

36. Abdulameer SA, Sulaiman SA, Hassali MA, et al. Osteoporosis and type 2 diabetes mellitus: what do we know, and what we can do? Patient Prefer Adherence. 2012;6:435-448.

37. Adami S. Bone health in diabetes: considerations for clinical management. Curr Med Res Opin. 2009;25(5):1057-1072.

38. Gerdhem $\mathrm{P}$, Isaksson $\mathrm{A}$, Akesson $\mathrm{K}$, et al. Increased bone density and decreased bone turnover, but no evident alteration of fracture susceptibility in elderly women with diabetes mellitus. Osteoporos Int. 2005;16(12):1506-1512.

39. Kanazawa I, Yamaguchi T, Yamamoto M, et al. Serum osteocalcin level is associated with glucose metabolism and atherosclerosis parameters in type 2 diabetes mellitus. J Clin Endocrinol Metab. 2009;94(1):45-49.

40. Sayinalp S, Gedik O, Koray Z. Increasing serum osteocalcin after glycemic control in diabetic men. Calcif Tissue Int. 1995;57(6):422-425.

41. Rosato MT, Schneider SH, Shapses SA. Bone turnover and insulinlike growth factor I levels increase after improved glycemic control in noninsulin-dependent diabetes mellitus. Calcif Tissue Int. 1998;63(2):107-111.

42. Dobnig H, Piswanger-Solkner JC, Roth M, et al. Type 2 diabetes mellitus in nursing home patients: effects on bone turnover, bone mass, and fracture risk. J Clin Endocrinol Metab. 2006;91(9):3355-3363.

43. Okazaki R, Totsuka Y, Hamano K, et al. Metabolic improvement of poorly controlled non-insulin dependent diabetes mellitus decreases bone turnover. J Clin Endocrinol Metab. 1997;82(9):2915-2920.

44. Kindblom JM, Ohlsson C, Ljunggren O, et al. Plasma osteocalcin is inversely related to fat mass and plasma glucose in elderly Swedish men. J Bone Miner Res. 2009;24(5):785-791.

45. Zinman B, Haffner SM, Herman WH, et al. Effect of rosiglitazone, metformin, and glyburide on bone biomarkers in patients with type 2 diabetes. J Clin Endocrinol Metab. 2010;95(1):134-142.
46. Stein EM, Liu XS, Nickolas TL, et al. Abnormal microarchitecture and reduced stiffness at the radius and tibia in postmenopausal women with fractures. J Bone Miner Res. 2010;25(12):2296- 2305.

47. Inaba M, Nishizawa Y, Mita K, et al. Poor glycemic control impairs the response of biochemical parameters of bone formation and resorption to exogenous 1,25-dihydroxyvitamin D3 in patients with type 2 diabetes. Osteoporos Int. 1999;9(6):525-531.

48. Inaba M, Terada M, Koyama $\mathrm{H}$, et al. Influence of high glucose on 1, 25dihydroxyvitamin D3-induced effect on human osteoblast-like MG-63 cells. J Bone Miner Res. 1995;10(7):1050-1056.

49. Terada M, Inaba M, Yano Y, et al. Growth-inhibitory effect of a high glucose concentration on osteoblast-like cells. Bone. 1998;22(1):17-23.

50. Akin O, Göl K, Aktürk M, et al. Evaluation of bone turnover in postmenopausal patients with type 2 diabetes mellitus using biochemical markers and bone mineral density measurements. Gynecol Endocrinol. 2003;17(1):19-29.

51. Razi F, Esmaili M, Esfahani EN, et al. Bone structure and turnover in postmenopausal women with type 2 diabetes mellitus. Menopause. 2016;23(3):280-285.

52. Shu A, Yin MT, Stein E, et al. Bone structure and turnover in type 2 diabetes mellitus. Osteoporos Int. 2012;23(2):635-641.

53. Saeed BO, Nixon SJ, Weaver JU. Peripheral Bone Mineral Density and Bone Turnover in Postmenopausal Women with Type 2 Diabetes. $J$ Diabetes Metab. 2012;S1:007.

54. Turner E, Vagula M, Devi S. Osteoporosis: An Understated Complication of Diabetes. US Pharm (Diabetes). 2009;34(5):14-16.

55. Abdulameer SA, Sulaiman SA, Hassali MA, et al. Osteoporosis and type 2 diabetes mellitus: what do we know, and what we can do? Patient Prefer Adherence. 2012;6:435-448.

56. Antonopoulou M, Bahtiyar G, Banerji MA, et al. Diabetes and bone health. Maturitas. 2013;76(3):253-259.

57. Saito M, Marumo K. Bone quality in diabetes. Front Endocrinol (Lausanne). 2013;4:72.

58. Hamada Y, Fujii H, Fukagawa M. Role of oxidative stress in diabetic bone disorder. Bone. 2009;45(Suppl 1):35S-38S.

59. Nalysnyk L, Hernandez-Medina M, Krishnarajah G. Glycaemic variability and complications in patients with diabetes mellitus: evidence from a systematic review of the literature. Diabetes Obes Metab. 2010;12(4):288-298. 